\title{
Afatinib Mediates Autophagic Degradation of ORAI1, STIM1, and SERCA2, Which Inhibits Proliferation of Non-Small Cell Lung Cancer Cells
}

\author{
Mi Seong Kim, Ph.D. ${ }^{1,2}$, So Hui Kim ${ }^{3}$, Sei-Hoon Yang, M.D., Ph.D. ${ }^{4}$ and Min Seuk Kim, Ph.D. ${ }^{1}$ (iD \\ ${ }^{1}$ Department of Oral Physiology, Institute of Biomaterial-Implant, School of Dentistry, Wonkwang University, Iksan, ${ }^{2}$ Wonkwang \\ Dental Research Institute, School of Dentistry, Wonkwang University, Iksan, ${ }^{3}$ Department of Carbon Convergence Engineering, \\ College of Engineering, Wonkwang University, Iksan, ${ }^{4}$ Department of Internal Medicine, School of Medicine, Wonkwang \\ University, Iksan, Republic of Korea
}

Background: The expression of calcium signaling pathway molecules is altered in various carcinomas, which are related to the proliferation and altered characteristics of cancer cells. However, changes in calcium signaling in anti-cancer drugresistant cells (bearing a T790M mutation in epidermal growth factor receptor [EGFR]) remain unclear.

Methods: Afatinib-mediated changes in the level of store-operated $\mathrm{Ca}^{2+}$ entry (SOCE)-related proteins and intracellular $\mathrm{Ca}^{2+}$ level in non-small cell lung cancer cells with T790M mutation in the EGFR gene were analyzed using western blot and ratiometric assays, respectively. Afatinib-mediated autophagic flux was evaluated by measuring the cleavage of LC3B-II. Flow cytometry and cell proliferation assays were conducted to assess cell apoptosis and proliferation.

Results: The levels of SOCE-mediating proteins (ORAI calcium release-activated calcium modulator 1 [ORAI1], stromal interaction molecule 1 [STIM1], and sarco/endoplasmic reticulum $\mathrm{Ca}^{2+}$ ATPase [SERCA2]) decreased after afatinib treatment in non-small cell lung cancer cells, whereas the levels of SOCE-related proteins did not change in gefitinibresistant non-small cell lung cancer cells (PC-9/GR; bearing a T790M mutation in EGFR). Notably, the expression level of SOCE-related proteins in PC-9/GR cells was reduced also responding to afatinib in the absence of extracellular $\mathrm{Ca}^{2+}$. Moreover, extracellular $\mathrm{Ca}^{2+}$ influx through the SOCE was significantly reduced in PC-9 cells pre-treated with afatinib than in the control group. Additionally, afatinib was found to decrease the level of SOCE-related proteins through autophagic degradation, and the proliferation of PC-9GR cells was significantly inhibited by a lack of extracellular $\mathrm{Ca}^{2+}$. Conclusion: Extracellular $\mathrm{Ca}^{2+}$ plays important role in afatinib-mediated autophagic degradation of SOCE-related proteins in cells with T790M mutation in the EGFR gene and extracellular $\mathrm{Ca}^{2+}$ is essential for determining anti-cancer drug efficacy.

Keywords: Afatinib; Calcium Channels; Non-Small Cell Lung; Autophagy

Address for correspondence: Sei-Hoon Yang, M.D., Ph.D.

Department of Internal Medicine, School of Medicine, Wonkwang University, 460 Iksan-daero, Iksan 54538, Republic of Korea

Phone: 82-63-859-2582, Fax: 82-63-855-2025, E-mail: yshpul@wku.ac.kr

Address for correspondence: Min Seuk Kim, Ph.D.

Department of Oral Physiology, Institute of Biomaterial-Implant, School of Dentistry, Wonkwang University, 460 Iksan-daero, Iksan 54538, Republic of Korea

Phone: 82-63-850-6997, Fax: 82-63-855-2025, E-mail: happy1487@wku.ac.kr

Received: Jul. 6, 2021, Revised: Aug. 26, 2021, Accepted: Oct. 24, 2021, Published online: Dec. 1, 2021

@(c) it is identical to the Creative Commons Attribution Non-Commercial License (http://creativecommons.org/licenses/by-nc/4.0/) 


\section{Introduction}

Increasing number of studies on the molecular pathology of cancer has led to discovery of various gene mutations in nonsmall cell lung cancer (NSCLC), and those genes further being studied as important components in the development of targeted therapy. In NSCLCs, epidermal growth factor receptor $(E G F R)$ exon 19 deletion and exon 21 L858R point mutations are most commonly observed ${ }^{1}$. In particular, genetic mutations in the EGFR tyrosine kinase domain mediate the sustained activity of EGFR kinase and induce cell proliferation ${ }^{2}$. Gefitinib and erlotinib are the first-generation EGFR tyrosine kinase inhibitors (TKIs) that reversibly bind to the ATP-binding site in the EGFR tyrosine kinase domain. These inhibitors are currently being used in clinical practice in some instances. Compared to the first-generation anti-cancer drugs, secondgeneration drugs such as afatinib and dacomitinib, irreversibly bind to the tyrosine kinase domain and inhibit EGFR (ErbB1), HER2 (ErbB2), and HER4 (ErbB4) receptor functions ${ }^{3,4}$. Moreover, the irreversible binding of afatinib to receptors can effectively inhibit cell proliferation in EGFR mutated cell lines resistant to erlotinib or gefitinib ${ }^{5}$.

Calcium ions $\left(\mathrm{Ca}^{2+}\right)$ are an essential secondary messenger in most cells that mediates various physiological cellular activities ${ }^{6}$, and abnormal $\mathrm{Ca}^{2+}$ signaling are closely related to the development of diseases, including cancer ${ }^{7}$. Sarco/endoplasmic Reticulum ATPase (SERCA) regulates the basal level of cytosolic free $\mathrm{Ca}^{2+}$ through transportation of $\mathrm{Ca}^{2+}$ into the endoplasmic reticulum (ER), and its pharmacological inhibition of SERCA induces depletion of $\mathrm{Ca}^{2+}$ in the $\mathrm{ER}^{8}$. Depletion of $\mathrm{Ca}^{2+}$ in the ER, which is intracellular $\mathrm{Ca}^{2+}$ storage, mediates extracellular $\mathrm{Ca}^{2+}$ influx into the cell, also known as storeoperated $\mathrm{Ca}^{2+}$ entry (SOCE). During this process, stromal interaction molecule 1 (STIM1) acts as a sensor of $\mathrm{ER} \mathrm{Ca}^{2+}$ store contents ${ }^{9}$. In breast cancer cells, ORAI calcium releaseactivated calcium modulator 1 (ORAI1) induces the influx of intracellular $\mathrm{Ca}^{2+}$ by interacting with the plasma membrane protein SPCA2, which leads to cell proliferation. Additionally, ORAI1 regulates cancer cell metastasis, which shows the correlation between $\mathrm{Ca}^{2+}$ channel proteins and proliferation and metastasis of cancer cells ${ }^{10}$. STIM1 binds to the plasma membrane $\mathrm{Ca}^{2+}$ channel, ORAIl, and promotes extracellular $\mathrm{Ca}^{2+}$ influx into cells ${ }^{11}$. Extracellular $\mathrm{Ca}^{2+}$ influx plays important roles in cell survival, cell proliferation, invasiveness ${ }^{12}$, and the regulation of the early G1 phase of the cell cycle ${ }^{13}$. Mulder et al. ${ }^{14}$ reported that afatinib treatment in PC-9 cells regulates the expression of various $\mathrm{Ca}^{2+}$ signal-mediated proteins and that the absence of extracellular $\mathrm{Ca}^{2+}$ enhances afatinib efficacy against NSCLC cells. However, there is a lack of understanding of afatinib-mediated changes in the extracellular $\mathrm{Ca}^{2+}$ influx and cytotoxicity according to changes in extracellular $\mathrm{Ca}^{2+}$ influx in cells with T790M gene mutation in EGFR.

In this study, autophagic flux and changes in the expression of ORAI1, STIM1, and sarco/endoplasmic reticulum Ca2+ ATPase (SERCA2) after afatinib treatment were assessed in PC-9 and gefitinib-resistant PC-9 (PC-9/GR) cells to understand cell responses in the presence and absence of extracellular $\mathrm{Ca}^{2+}$. Further, the effects of extracellular $\mathrm{Ca}^{2+}$ absence on afatinib-mediated inhibition of cell proliferation were evaluated.

\section{Materials and Methods}

\section{Cell culture and reagents}

PC-9 and PC-9/GR cell lines were provided by Dr. Jin Kyung Roh (Asan Medical Center, Asan Medical Institute of Convergence Science and Technology). Cells were cultured in RPMI-1640 medium (Hyclone, Logan, UT, USA) with 10\% fetal bovine serum and $100 \mathrm{U} / \mathrm{mL}$ penicillin-streptomycin in a $5 \% \mathrm{CO}_{2}$ incubator at $37^{\circ} \mathrm{C}$. Anti-Orail, -proliferating cell nuclear antigen (PCNA), goat anti-rabbit horseradish peroxidase (HRP) secondary antibody, and goat anti-mouse HRP secondary antibodies were purchased from Santa Cruz Biotechnology (Dallas, TX, USA). Anti-LC3B, -STIM1, -SERCA2, -poly(ADP-ribose) polymerase (PARP), - $\beta$-actin antibodies were purchased from Cell Signaling Technology, Inc. (Danvers, MA, USA). Afatinib was purchased from Selleckchem (Houston, TX, USA), and cyclopiazonic acid (CPA) was purchased from Enzo Life Sciences (Farmingdale, NY, USA). Bafilomycin A and 3-methyladenine (3-MA) were purchased from SigmaAldrich (St. Louis, MO, USA).

\section{Western blot assay}

Cells were collected after centrifuging at $4,000 \mathrm{rpm}$ and $4^{\circ} \mathrm{C}$ for 4 minutes. RIPA buffer (Thermo Fisher Scientific, Foster City, CA, USA) containing Protease \& Phosphatase Inhibitor (Thermo Fisher Scientific) was added to lyse the cells. Proteins were separated using sodium dodecyl sulfate polyacrylamide gel electrophoresis and transferred to a PVDF membrane (GE Healthcare, Little Chalfont, Notts, UK). The membrane was then blocked using TBS-T mixed with 5\% (w/v) skim milk and incubated for 2 hours at $4^{\circ} \mathrm{C}$ in a rocker, and then washed four times for 10 minutes each time using TBS containing $0.1 \%$ Tween-20. The membrane was incubated with primary antibody diluted at a ratio of 1:1,000 in 5\% skim milk solution overnight at $4^{\circ} \mathrm{C}$ in a rocker. The following day, the membrane was washed four times for 10 minutes each time using TBS containing $0.1 \%$ tween-20. Then it was incubated with HRPconjugated secondary antibody diluted at a ratio of 1:2,000 in a rocker for 2 hours at $4^{\circ} \mathrm{C}$, and washed again four times for 10 minutes each time using TBS containing 0.1\% Tween-20. The membrane was then treated with a 1:1 mix of SuperSignal West Pico PLUS Luminol/Enhancer solution and SuperSignal 
West Pico PLUS Stable Peroxide (Thermo Fisher Scientific). Protein bands were detected using AzureSpot 2.0 (AzureBiosystems, Dublin, CA, USA).

\section{Intracellular $\mathrm{Ca}^{2+}$ measurement}

Fura-2/AM (Sigma-Aldrich), which is a fluorescent dye used to detect $\mathrm{Ca}^{2+}$, was used to measure intracellular $\mathrm{Ca}^{2+}$ $\left(\left[\mathrm{Ca}^{2+}\right] \mathrm{i}\right)$. A $1 \mu \mathrm{M}$ Fura-2/AM solution was added to the cell culture medium in a $5 \% \mathrm{CO}_{2}$ incubator at $37^{\circ} \mathrm{C}$. The cell surface was washed briefly using HEPES buffer with a $\mathrm{pH}$ of 7.4 and osmotic pressure of $310 \mathrm{mOsm}$. $\left[\mathrm{Ca}^{2+}\right] \mathrm{i}$ was measured using Fura-2/AM at 340 and $380 \mathrm{~nm}$. Fluorescence at $510 \mathrm{~nm}$ was captured using a CCD (charge-coupled device) camera. Captured images were analyzed using MetaFluor software (Molecular Devices, San Jose, CA, USA) and expressed as $\mathrm{F}_{340} /$ $\mathrm{F}_{380}$ ratio.

\section{Flow cytometry}

FITC Annexin V Apoptosis Detection Kit with propidium iodide (PI) (BioLegend, San Diego, CA, USA) was used to assess cell apoptosis. In summary, cells were detached using trypsin-EDTA and washed twice with cold phosphate buffered saline. After cells were washed with cell staining buffer, they were then incubated with cell staining buffer containing Annexin V-FITC and PI for 15 minutes in the dark. The stained cells were analyzed using a FACScan analyzer (Becton Dickinson Frankin Lakes, NJ, USA), and a minimum of 20,000 events were analyzed.

\section{Cell proliferation assay}

Cell proliferation was assessed using EZ-CYTOX (Daeil Lab Service Co. Ltd., Seoul, Korea) according to the manufacturer's protocol. Cells were plated in a 96-well plate and treated according to the experiment design. The cells were then incubated in a $5 \% \mathrm{CO}_{2}$ incubator at $37^{\circ} \mathrm{C}$. After 72 hours, EZ-Cytox $(10 \mu \mathrm{L})$ was added to each well, and cells were incubated at $37^{\circ} \mathrm{C}$ and with $5 \% \mathrm{CO}_{2}$ for 30 minutes. Optical density was measured at $450 \mathrm{~nm}$ using iMAX Microplate Reader (Bio-Rad, Hercules, CA, USA).

\section{Statistical analysis}

Origin 2020 software (OriginLab Corporation, Northampton, MA, USA) was used to compare the statistical significance between the groups. One-way analysis of variance and t-test were conducted to assess significance, and Tukey's post hoc test was conducted for post hoc analysis. $\mathrm{p}<0.05$ was considered statistically significant. All results were obtained from three or more independent experiments and expressed as mean \pm SD.

\section{Results}

\section{Afatinib-mediated alterations in the expression of} ORAI1, STIM1, and SERCA2 proteins in the presence and absence of extracellular $\mathrm{Ca}^{2+}$

Alterations in the expression of $\mathrm{Ca}^{2+}$ channels and $\mathrm{Ca}^{2+}-$ binding proteins in lung cancer cells regulate cell proliferation and apoptosis signaling pathways ${ }^{15}$. In particular, expression of STIM1, 2 and ORAII, 2, and 3, which mediate the extracellular $\mathrm{Ca}^{2+}$ influx in non-excitable cells, were altered in tissues of various cancers, including breast and colorectal cancers ${ }^{16}$. We examined the levels of ORAI1, STIM1, and SERCA2, which are directly related to SOCE, after treating PC-9 and PC-9/GR cells with afatinib. PC-9 and PC-9/GR cells were cultured in a normal culture medium $\left(1 \mathrm{mM} \mathrm{CaCl}{ }_{2}\right)$ and $\mathrm{Ca}^{2+}$-free culture medium $\left(0 \mathrm{mM} \mathrm{CaCl}_{2}\right)$, and cells were treated with $0.1 \mu \mathrm{M}$ afatinib for different durations of time (0, 24, and 48 hours). The whole-cell lysates were used to assess the intracellular levels of ORAI1, STIM1, and SERCA2 proteins through western blot assay. In PC-9 cells that were cultured in a normal medium ( $\left.1 \mathrm{mM} \mathrm{CaCl}_{2}\right)$, intracellular expression of ORAIl, STIM1, and SERCA2 proteins were significantly decreased after 48 hours of treatment with afatinib. In contrast, the levels of ORAI1, STIM1, and SERCA2 proteins in PC-9/GR cells were not decreased after afatinib treatment (Figure 1A). In PC-9 and PC-9/GR cells cultured in $\mathrm{Ca}^{2+}$-free medium $(0 \mathrm{mM}$ $\mathrm{CaCl}_{2}$ ), expression of ORAI1, STIM1, and SERCA2 proteins were significantly reduced after afatinib treatment (Figure 1B). These results suggested that a decreased expression of SOCEmediating proteins by afatinib depends on extracellular $\mathrm{Ca}^{2+}$.

\section{Reduction in SOCE in PC-9 cells by afatinib}

A ratiometric assay using a fluorescent $\mathrm{Ca}^{2+}$ indicator was performed to confirm the decrease in SOCE based on the reduced levels of ORAI1, STIM1, and SERCA2 proteins in PC-9 cells after afatinib treatment. PC-9 cells cultured in a normal medium $\left(1 \mathrm{mM} \mathrm{CaCl}_{2}\right)$ were treated for 48 hours with afatinib $(0.1 \mu \mathrm{M})$ or DMSO (control). CPA $(25 \mu \mathrm{M})$ was diluted in a $\mathrm{Ca}^{2+}$-free HEPES buffer (1 mM EGTA) and perfused to cells to induce $\mathrm{ER} \mathrm{Ca}^{2+}$ depletion. The cells were then treated with CPA $(25 \mu \mathrm{M})$ diluted in a normal HEPES buffer $\left(1 \mathrm{mM} \mathrm{Ca}^{2+}\right)$ to measure SOCE. SOCE significantly decreased in experimental group pre-treated with afatinib $(0.31031 \pm 0.09007$, $\mathrm{n}=10)$ compared to that in the control group $(0.59053 \pm 0.11451$, $\mathrm{n}=11$ ) (Figure 2).

\section{Reduced expression of ORAI1, STIM1, and SERCA2 after afatinib treatment depends on autophagy}

To confirm that the decrease of ORAI1, STIM1, and SERCA2 expression after afatinib treatment was due to intracellular au- 
A


B
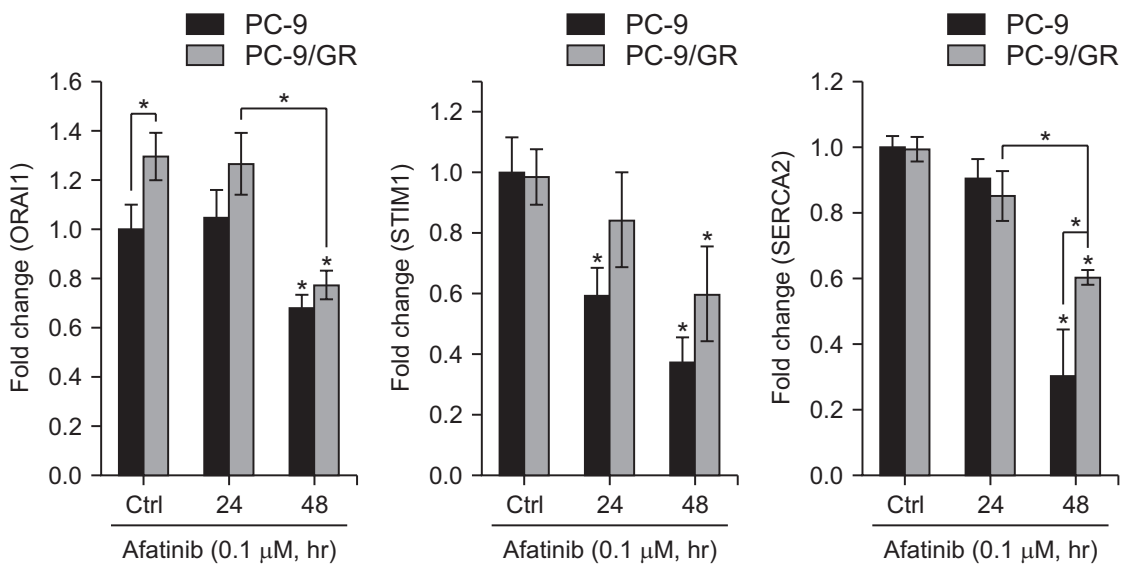

Figure 1. Effects of low extracellular $\mathrm{Ca}^{2+}$ on ORAI calcium release-activated calcium modulator 1 (ORAI1), stromal interaction molecule 1 (STIM1), and sarco/endoplasmic reticulum Ca2+ ATPase (SERCA2) expression in afatinib-treated PC-9 and PC-9/GR. PC-9 and PC-9/ GR cells were incubated with afatinib $(0.1 \mu \mathrm{M})$ for varying durations. Expression of ORAI1, STIM1, and SERCA2 in PC-9 and PC-9/GR cells, cultured in normal culture medium $\left(1 \mathrm{mM} \mathrm{CaCl}_{2}\right)(\mathrm{A})$ and $\mathrm{Ca}^{2+}$-free culture medium $(0 \mathrm{mM} \mathrm{CaCl})(\mathrm{B})$, was determined using western blot. $\beta$-Actin was used as a loading control. The bar graph shows relative fold change of each protein in afatinib-treated cells compared with those in control (no afatinib). Data are represented as mean \pm standard deviation. ${ }^{*} \mathrm{p}<0.05$ and compared with control or between the indicated groups.
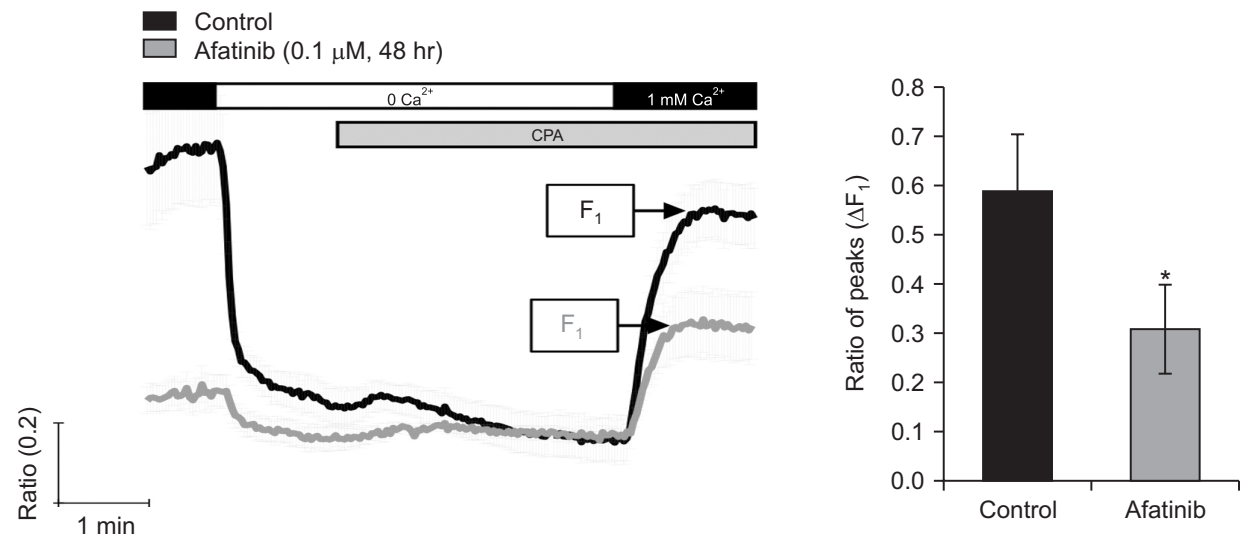

Figure 2. Reduction of store-operated $\mathrm{Ca}^{2+}$ entry (SOCE) in afatinib pre-treated PC-9 cells. PC-9 cells loaded with Fura-2/ AM were used to determine the intracellular $\mathrm{Ca}^{2+}\left(\left[\mathrm{Ca}^{2+}\right] \mathrm{i}\right)$ response to afatinib $(0.1 \mu \mathrm{M}, 48$ hours $)$. $\left[\mathrm{Ca}^{2+}\right] \mathrm{i}$ entry via $\operatorname{SOCE}\left(\Delta \mathrm{F}_{1}\right)$ was measured by sequential perfusion of cyclopiazonic acid $(25 \mu \mathrm{M})$ with and without exogenous $\mathrm{Ca}^{2+}$. Data are represented as mean \pm standard deviation. ${ }^{*} \mathrm{p}<0.05$.

tophagy, LC3B-II cleavage was assessed at specific time points after treating PC-9 and PC-9/GR cells with afatinib. Afatinib $(0.1 \mu \mathrm{M})$-mediated LC3B-II cleavage in PC-9 cells was signifi- cantly increased after 1 and 3 hours of treatment. However, no significant change was observed in PC-9/GR cells (Figure 3A). After 3 and 6 hours of treatment with afatinib, significantly dif- 
A


B
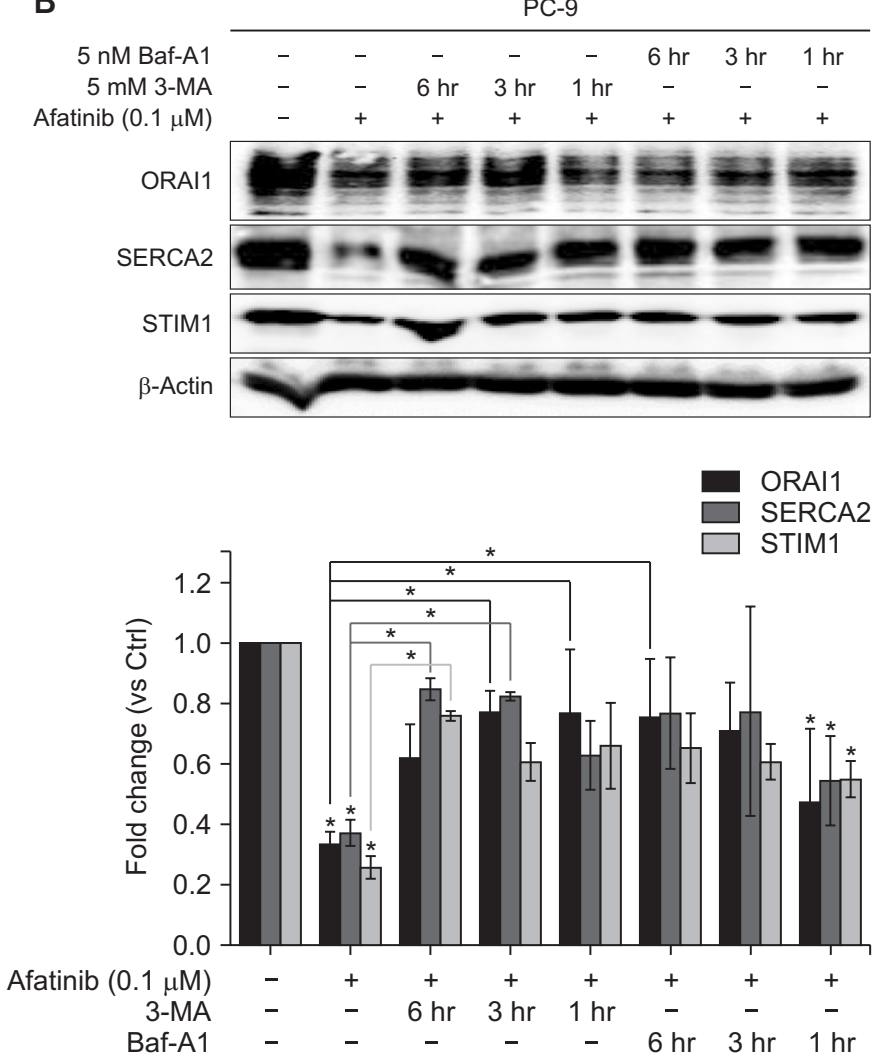

Figure 3. Afatinib-mediated degradation of ORAI calcium release-activated calcium modulator 1 (ORAI1), stromal interaction molecule 1 (STIM1), and sarco/endoplasmic reticulum Ca2+ ATPase (SERCA2) is suppressed by autophagy inhibitors, 3-methyladenine (3-MA) and bafilomycin A1. (A) PC-9 and PC-9/GR cells were incubated with afatinib $(0.1 \mu \mathrm{M})$ for varying durations $(0,1,3,6$, and 36 hours). Following the incubation under the indicated conditions, whole-cell lysates were used to determine the cleavage of LC3B. $\beta$-Actin levels were used as loading controls. The bar graph shows the relative fold change of LC3B-II in afatinib-treated cells compared with those in control (no afatinib). (B) Afatinib $(0.1 \mu \mathrm{M})$ was added to PC-9 cells. Cells were then treated with 3-MA (5 mM) and bafilomycin A1 (5 nM) for 6, 3, and 1 hour and then harvested. Expression of ORAI1 (24-hour incubation), STIM1 (48-hour incubation), and SERCA2 (48-hour incubation) were evaluated using western blot. $\beta$-Actin levels were used as loading controls. The bar graph shows the relative fold change of each protein in afatinib-treated cells compared with that in control. Data are represented as mean \pm standard deviation. ${ }^{*} \mathrm{p}<0.05$ and compared with control or between the indicated groups.

ferent LC3B-II cleavage levels were observed between PC-9 and PC-9/GR cells (Figure 3A). To further determine the association between decreased expression of ORAI1, STIM1, and SERCA2 and intracellular autophagy activity, bafilomycin A1 (5 $\mathrm{nM})$ and 3-MA ( $5 \mathrm{mM})$, which are autophagy inhibitors, were added for the last 1, 3, and 6 hours of afatinib (0.1 $\mu \mathrm{M}$ ) treatment (ORAI1 for 24 hours; STIM1 and SERCA2 for 48 hours). Reduced ORAI1, STIM1, and SERCA2 levels were significantly inhibited by bafilomycin Al and 3-MA treatment (Figure 3B). These findings suggest that decreased level of SOCE-mediating proteins by afatinib depends on the intracellular autophagic degradation.

\section{Analysis of afatinib-mediated apoptosis in the presence and absence of extracellular $\mathrm{Ca}^{2+}$}

We demonstrated that afatinib reduces ORAI1, STIM1, and SERCA2 protein levels in PC-9/GR cells in the absence of extracellular $\mathrm{Ca}^{2+}$. Therefore, we assumed that the absence of extracellular $\mathrm{Ca}^{2+}$ would regulate apoptosis of PC-9 and PC-9/ GR cells, and flow cytometry was used to test this hypothesis. PC-9 and PC-9/GR cells were cultured in experimental conditions of different calcium concentrations and afatinib treatment times. Apoptosis was then assessed by measuring the fluorescence levels of propidium iodide and FITC. In PC-9 cells, similar to the decreased expression of ORAI1, STIM1, and SERCA2 at 48 hours, apoptotic cells increased by $>40 \%$ under all conditions, with and without extracellular $\mathrm{Ca}^{2+}$. However, although ORAI1, STIM1, and SERCA2 protein levels de- 
creased in the absence of extracellular $\mathrm{Ca}^{2+}$ in PC-9/GR cells, there was no difference in the percentage of apoptotic cells (Figure 4).

\section{Lack of extracellular $\mathrm{Ca}^{2+}$ enhances the inhibitory effects of afatinib on the proliferation of PC-9/GR cells}

To determine inhibition level of PC-9 and PC-9/GR cell proliferation by afatinib without extracellular $\mathrm{Ca}^{2+}$, the expression
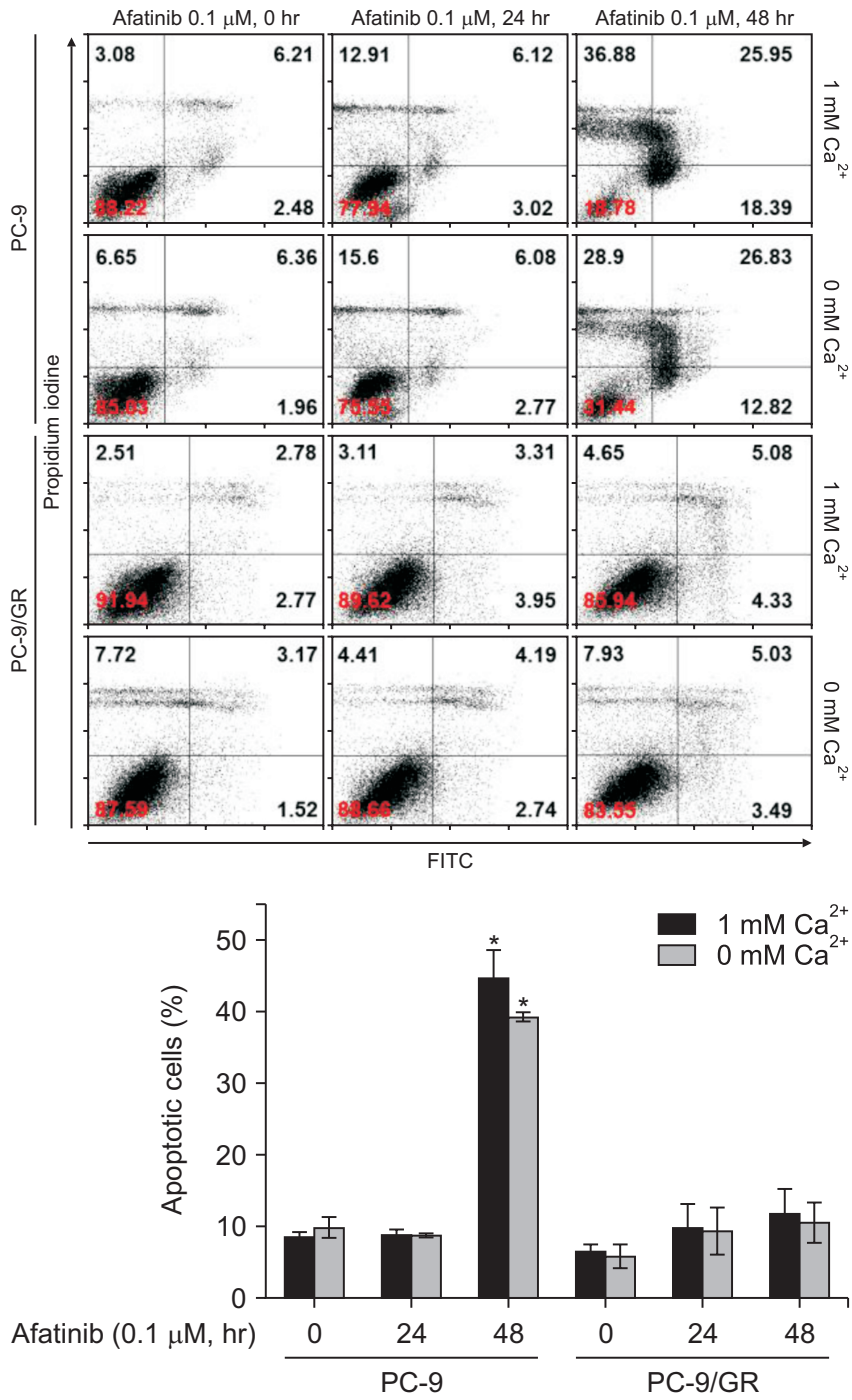

Figure 4. Effects of low extracellular $\mathrm{Ca}^{2+}$ on the afatinib-mediated apoptotic cell death. PC-9 and PC-9/GR cells were incubated with afatinib $(0.1 \mu \mathrm{M})$ with or without exogenous $\mathrm{Ca}^{2+}$ for different time periods (up to 48 hours). Following the incubation, cells were stained with Annexin V-FITC and 20,000 cells and apoptotic cells were evaluated using flow cytometry. The percentage of apoptotic cells were presented as mean \pm standard deviation. ${ }^{*} \mathrm{p}<0.05$ and compared with control. of PCNA, a marker protein for cell proliferation, and cleavage of PARP, a marker protein for cytotoxicity, were assessed. In addition, cell proliferation was evaluated by MTT assay. In PC-9 cells, the expression of PCNA was decreased by afatinib regardless of extracellular $\mathrm{Ca}^{2+}$, and PARP cleavage increased in the absence of extracellular $\mathrm{Ca}^{2+}$ (Figure 5A). In PC-9/GR cells, PCNA expression was not affected by afatinib when the extracellular $\mathrm{Ca}^{2+}$ level was normal. Additionally, intracellular PCNA expression was decreased after 48 hours of treatment with afatinib without extracellular $\mathrm{Ca}^{2+}$ (Figure 5B). Notably, PARP cleavage in PC-9/GR cells after afatinib treatment was not observed regardless of extracellular $\mathrm{Ca}^{2+}$ (Figure 5A). PC-9 and PC-9/GR cells were cultured with and without extracellular $\mathrm{Ca}^{2+}$, and cell proliferation was assessed after 72 hours of treatment with afatinib $(0.1 \mu \mathrm{M})$. The viability of PC-9 cells was reduced by $>50 \%$ after afatinib $(0.1 \mu \mathrm{M})$ treatment under all conditions, with and without extracellular $\mathrm{Ca}^{2+}$. The viability of PC-9/GR cells was reduced by $15 \%$ after afatinib $(0.1 \mu \mathrm{M})$ treatment in the presence of extracellular $\mathrm{Ca}^{2+}$. In the absence of extracellular $\mathrm{Ca}^{2+}$, the viability of cells was reduced by $>30 \%$ after afatinib $(0.1 \mu \mathrm{M})$ treatment. These findings suggest that lack of extracellular $\mathrm{Ca}^{2+}$ further improved the inhibitory effects of afatinib on PC-9/GR cell proliferation.

\section{Discussion}

The concentration of intracellular $\mathrm{Ca}^{2+}$ is regulated by various intracellular molecules, known as the "calcium-signaling toolkit." Intracellular calcium ions are precisely controlled spatially and temporally to mediate various cellular physiological activities, including cell proliferation, differentiation, migration, and secretion ${ }^{6}$. Moreover, abnormal $\mathrm{Ca}^{2+}$ signals are also correlated to the development of various diseases. In particular, abnormal changes in the expression of "calciumsignaling toolkit" proteins were reported in various carcinoma cells, and these changes mediate the induction of tumorigenesis in normal cells, tissue invasion and metastasis of cancer cells, and resistance to anti-cancer drugs ${ }^{7}$. In a recent study, Mulder et al. reported that intracellular $\mathrm{Ca}^{2+}$ signaling plays a key role in reactivating the mammalian target of rapamycin (mTOR) and mitogen-activated protein kinase signaling pathways inhibited by afatinib in NSCLC cells over time ${ }^{14}$. Notably, apoptosis and inhibition of proliferation by afatinib were regulated by extracellular $\mathrm{Ca}^{2+}$ level, and the absence of exogenous calcium significantly improved afatinib efficacy ${ }^{14}$. Afatinib is an irreversible ErbB receptor family blocker and inhibits ATPbinding against tumors with exon 19 deletion, exon 21 L858R mutation, and exon 20 T790M mutation ${ }^{17}$. Additionally, afatinib has high inhibitory activity on cell proliferation against carcinomas resistant to first-generation EGFR-TKIs, including gefitinib and erlotinib ${ }^{17}$. However, changes in the "calciumsignaling toolkit" in NSCLC cells resistant to first-generation 
A



B

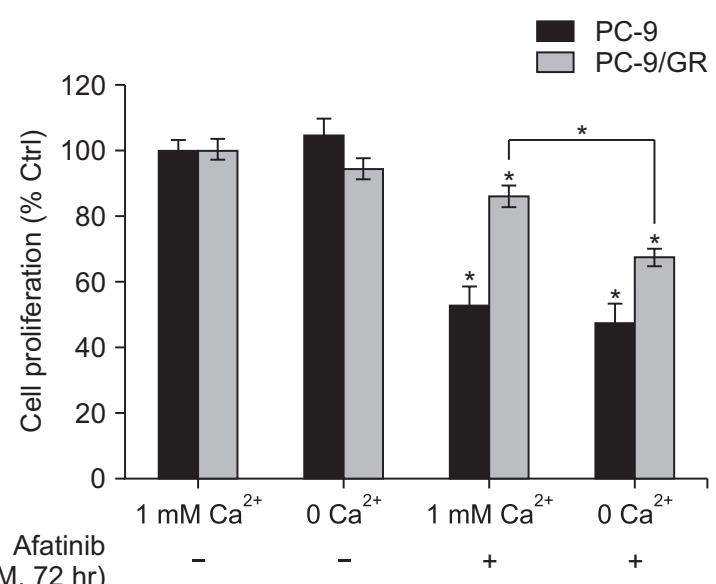

Figure 5. Low extracellular $\mathrm{Ca}^{2+}$ enhances afatinib-mediated reduction of cell proliferation. PC-9 and PC-9/GR cells were cultured under the indicated conditions and were respectively used for western blot (A) and cell proliferation assay (B). (A) Whole-cell lysates were collected and applied to evaluate expression levels of proliferating cell nuclear antigen (PCNA) and poly(ADP-ribose) polymerase (PARP) cleavage. $\beta$-Actin levels were used as loading controls. (B) Following the incubation, cells were fixed and stained to determine cell proliferation. Data are presented relative to control $\left(1 \mathrm{mM} \mathrm{Ca}^{2+} \mathrm{w} / \mathrm{o}\right.$ afatinib) and as mean \pm standard deviation. ${ }^{*} \mathrm{p}<0.05$ and compared with control.

EGFR-TKIs, such as gefitinib, are not well known. In this study, we assessed the alterations in the expression of SOCEmediating proteins by afatinib and the resulting changes in the physiological activities in a PC-9 cell line and a gefitinibresistant PC-9/GR cell line (bearing a T790M mutation in EGFR gene). The expression of ORAI1, STIM1, and SERCA2 proteins in PC-9 cells was significantly decreased after treatment with afatinib for 48 hours regardless of extracellular $\mathrm{Ca}^{2+}$. In cells resistant to gefitinib, there was no significant change in protein levels after afatinib treatment in an environment with a normal level of extracellular $\mathrm{Ca}^{2+}(1 \mathrm{mM})$. However, in the absence of extracellular $\mathrm{Ca}^{2+}$, afatinib treatment caused a significant decrease in protein levels (Figure 1). Notably, afatinib, which has obvious inhibitory effects on the proliferation of cells with T790M gene mutation, did not affect ORAI1, STIM1, and SERCA2 protein levels in PC-9/GR cells, unlike in PC-9 cells in the presence of extracellular $\mathrm{Ca}^{2+}$. Additionally, in the absence of extracellular $\mathrm{Ca}^{2+}$, protein levels were decreased by afatinib in both PC-9 and PC-9/GR cells. These results indicate that the cellular response to afatinib is altered by a T790M gene mutation and in PC-9/GR cells, the presence of exogenous calcium determines the levels of proteins that mediate SOCE.

In 2007, Hoyer-Hansen and Jaattela ${ }^{18}$ reported that an increase in intracellular $\mathrm{Ca}^{2+}$ was fundamental in the early stages of LC3 aggregation and autophagosome formation. It was shown that $\mathrm{Ca}^{2+}$-dependent AMP that activated protein kinase inhibits target of rapamycin (mTOR) activity, thereby promoting the autophagic influx ${ }^{18}$. We observed an increase in autophagic influx triggered by afatinib presence in PC-9 cells. However, there was no significant increase in autophagic flux in PC-9/GR cells. This finding is consistent with the decrease in the expression of SOCE-mediating proteins (ORAI1, STIM1, and SERCA2) by afatinib and suggests that afatinib decreases protein levels through autophagic degradation. Further, we observed that afatinib effectively inhibited cell proliferation in PC-9/GR cells without extracellular $\mathrm{Ca}^{2+}$ more than with extracellular $\mathrm{Ca}^{2+}$. This finding shows that extracellular $\mathrm{Ca}^{2+}$ plays a crucial role in afatinib-mediated suppression of SOCE-related proteins and regulation of cell proliferation.

The findings of this study suggest that the expression of SOCE-mediating proteins (ORAI1, STIM1, and SERCA2) are decreased by afatinib-activated autophagic degradation and demonstrates that extracellular $\mathrm{Ca}^{2+}$ levels increase the efficacy of afatinib. Therefore, the concentration of extracellular $\mathrm{Ca}^{2+}$ is an important factor in enahncing the efficiency of anticancer treatment using afatinib.

\section{Authors' Contributions}

Conceptualization: Yang SH, Kim MS (Mi Seong Kim). Formal analysis: Yang SH, Kim MS (Min Seuk Kim), Kim MS (Mi Seong Kim). Data curation: Kim MS (Mi Seong Kim), Kim SH. Investigation: Kim MS (Mi Seong Kim), Kim SH. Writing - original draft preparation: Yang SH, Kim MS (Min Seuk Kim), Kim MS (Mi Seong Kim). Approval of final manuscript: all authors.

\section{Conflicts of Interest}

No potential conflict of interest relevant to this article was reported. 


\section{Acknowledgments}

We thank Dr. Jin Kyung Rho for providing us with different NSCLC cell lines. We would like to thank Editage (https:// www.Editage.co.kr) for English language editing.

\section{Funding}

This study was funded by the Korean Association for the Study of Targeted Therapy (KASTT) [Korean Association for Lung Cancer (KASTT-20200111)] and Basic Science Research Program through the National Research Foundation of Korea (NRF) funded by the Ministry of Education, Science and Technology [NRF-2020R1I1A3052198].

\section{References}

1. Harrison PT, Vyse S, Huang PH. Rare epidermal growth factor receptor $(E G F R)$ mutations in non-small cell lung cancer. Semin Cancer Biol 2020;61:167-79.

2. Stella GM, Luisetti M, Inghilleri S, Cemmi F, Scabini R, Zorzetto $\mathrm{M}$, et al. Targeting EGFR in non-small-cell lung cancer: lessons, experiences, strategies. Respir Med 2012;106:173-83.

3. Krawczyk P, Kowalski DM, Ramlau R, Kalinka-Warzocha E, Winiarczyk K, Stencel K, et al. Comparison of the effectiveness of erlotinib, gefitinib, and afatinib for treatment of nonsmall cell lung cancer in patients with common and rare EGFR gene mutations. Oncol Lett 2017;13:4433-44.

4. Harvey RD, Adams VR, Beardslee T, Medina P. Afatinib for the treatment of EGFR mutation-positive NSCLC: a review of clinical findings. J Oncol Pharm Pract 2020;26:1461-74.

5. Kim SM, Kwon OJ, Hong YK, Kim JH, Solca F, Ha SJ, et al. Activation of IL-6R/JAK1/STAT3 signaling induces de novo resistance to irreversible EGFR inhibitors in non-small cell lung cancer with T790M resistance mutation. Mol Cancer Ther 2012;11:2254-64.

6. Berridge MJ, Bootman MD, Roderick HL. Calcium signalling: dynamics, homeostasis and remodelling. Nat Rev Mol Cell Biol 2003;4:517-29.

7. Stewart TA, Yapa KT, Monteith GR. Altered calcium signaling in cancer cells. Biochim Biophys Acta 2015;1848:2502-11.

8. Sehgal P, Szalai P, Olesen C, Praetorius HA, Nissen P, Christensen SB, et al. Inhibition of the sarco/endoplasmic reticulum (ER) $\mathrm{Ca}(2+)$-ATPase by thapsigargin analogs induces cell death via $\mathrm{ER} \mathrm{Ca}(2+)$ depletion and the unfolded protein response. J Biol Chem 2017;292:19656-73.

9. Mercer JC, Dehaven WI, Smyth JT, Wedel B, Boyles RR, Bird GS, et al. Large store-operated calcium selective currents due to co-expression of Orail or Orai2 with the intracellular calcium sensor, Stim1. J Biol Chem 2006;281:24979-90.

10. Feng M, Grice DM, Faddy HM, Nguyen N, Leitch S, Wang Y, et al. Store-independent activation of Orail by SPCA2 in mammary tumors. Cell 2010;143:84-98.

11. Derler I, Jardin I, Romanin C. Molecular mechanisms of STIM/Orai communication. Am J Physiol Cell Physiol 2016;310:C643-62.

12. Roderick HL, Cook SJ. Ca2+ signalling checkpoints in cancer: remodelling $\mathrm{Ca} 2+$ for cancer cell proliferation and survival. Nat Rev Cancer 2008;8:361-75.

13. Deliot N, Constantin B. Plasma membrane calcium channels in cancer: Alterations and consequences for cell proliferation and migration. Biochim Biophys Acta 2015;1848:2512-22.

14. Mulder C, Prust N, van Doorn S, Reinecke M, Kuster B, van Bergen En Henegouwen P, et al. Adaptive resistance to EGFRtargeted therapy by calcium signaling in NSCLC cells. Mol Cancer Res 2018;16:1773-84.

15. Yang H, Zhang Q, He J, Lu W. Regulation of calcium signaling in lung cancer. J Thorac Dis 2010;2:52-6.

16. Chen YF, Lin PC, Yeh YM, Chen LH, Shen MR. Store-operated $\mathrm{Ca}(2+)$ entry in tumor progression: from molecular mechanisms to clinical implications. Cancers (Basel) 2019;11:899.

17. Nelson V, Ziehr J, Agulnik M, Johnson M. Afatinib: emerging next-generation tyrosine kinase inhibitor for NSCLC. Onco Targets Ther 2013;6:135-43.

18. Hoyer-Hansen M, Jaattela M. AMP-activated protein kinase: a universal regulator of autophagy? Autophagy 2007;3:381-3. 